Published in final edited form as:

Org Lett. 2007 August 2; 9(16): 3153-3156.

\title{
Double Conjugate Addition of a Nitropropionate Ester to a Quinone Monoketal: Synthesis of an Advanced Intermediate to ( \pm )- Gelsemine
}

\author{
Scott Grecian and Jeffrey Aubé \\ Department of Medicinal Chemistry, 1251 Wescoe Hall Drive, Room 4070, Malott Hall, The \\ University of Kansas, Lawrence, Kansas 66045-7582, jaube@ku.edu
}

\begin{abstract}

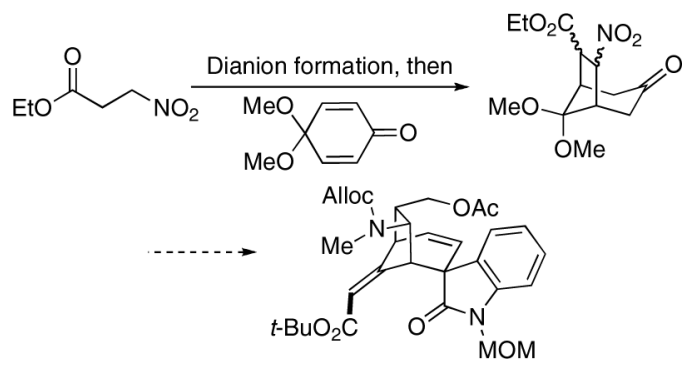

A double conjugate addition between the lithium dianion of ethyl 3-nitropropionate and $p$ benzoquinone dimethyl ketal afforded a mixture of diastereomeric [3.2.1]bicylooctanones. These products were converted into an advanced intermediate previously carried forward to $( \pm)$-gelsemine by Fukuyama and Liu.
\end{abstract}

Gelsemine (1) is the principal component of Gelsemium sempervirens, also known as yellow jasmine or Carolina jasmine, and was first reported in $1870 .{ }^{1}$ More than 70 years of chemical degradation studies established that gelsemine contained the same five functional groups as strychnine but provided little information about its complex skeleton. In 1959, Conroy and Chakrabarti proposed the now accepted structure of gelsemine, ${ }^{2}$ which was verified through $\mathrm{X}$-ray crystallographic analysis. ${ }^{3}$ 


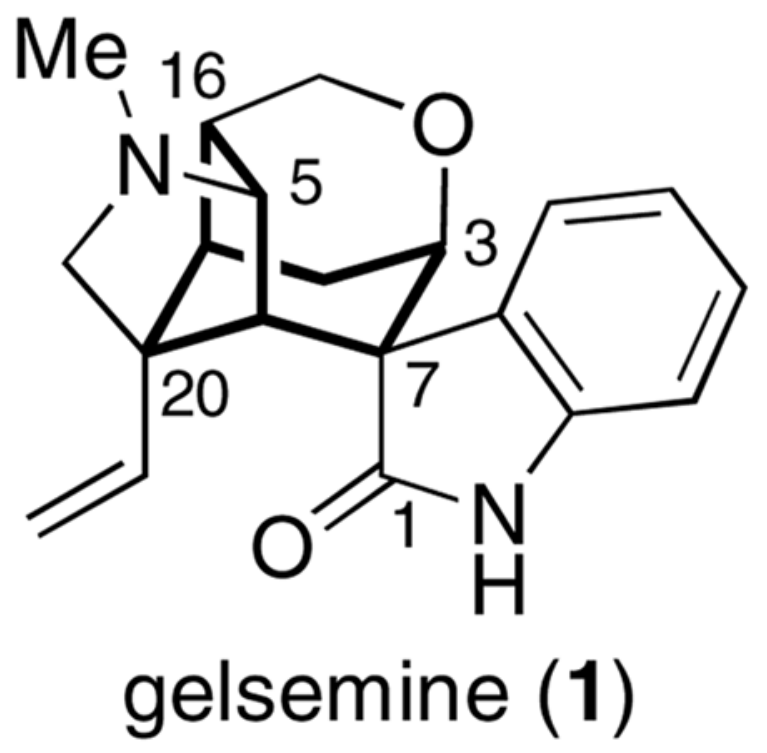

Gelsemine's complex structure has attracted considerable attention from the synthetic community. ${ }^{4}$ Following initial efforts mounted in the 1960's, the first total syntheses were reported by the research groups of Johnson and Speckamp in 1994. Additional racemic syntheses have been achieved by the Hart, Fukuyama, Overman, and Danishefsky research groups, 5 with one asymmetric synthesis reported by Fukuyama in $2000 .^{6}$

Herein, we report a new approach to gelsemine that involves the one-step synthesis of a functionalized [3.2.1]bicyclooctanone 2 from the dimethyl quinone ketal of benzoquinone (Scheme 1). We felt that the central location of this bicyclic ring system made it an attractive starting point for gelsemine synthesis. In this paper, we describe the synthesis of $\mathbf{2}$ via a double conjugate addition reaction and its conversion into a key intermediate to $( \pm)$-gelsemine reported by Fukuyama and coworkers. $5 \mathrm{e}$

In previous work, we surveyed the regioselective double conjugate additions of a series of bifunctional nucleophiles to quinone ketals. ${ }^{7}$ Although 1,3-bisnucleophiles such as ethyl acetoacetate routinely afforded [3.3.1]bicyclooctanone products using KO- $t$-Bu in THF, we could not extend this methodology to 1,2-bisnucleophiles under those conditions. In particular, when 1.0 equiv of quinone monoketal ester $\mathbf{4}$ was treated with 1.0 equiv of ethyl 3-

nitropropionate and KO- $t$-Bu in THF, adduct 5 formed. This material could not be induced to undergo a second, intramolecular addition under any conditions (Scheme 2). It is likely that any subsequent deprotonation only occurs $\alpha$ to the nitro group in $\mathbf{5}$ due to the large difference in $\mathrm{pK}_{\mathrm{a}}$ between the protons $\alpha$ to the ester $\left(\mathrm{pK}_{\mathrm{a}}=25\right)$ and the nitro group $\left(\mathrm{pK}_{\mathrm{a}}=10\right)$. If so, we surmised that if initial conjugate addition could be effected $\alpha$ to the ester, a second conjugate addition $\alpha$ to the nitro group should be facile.

Seebach and coworkers reported direct functionalization of methyl 3-nitropropionate $\alpha$ to the ester by generation of the corresponding dianions and subsequent treatment with electrophiles (Scheme 2). ${ }^{8}$ Thus, generation of the lithium dianion of ethyl 3-nitropropionate (2.1 equiv LDA, THF, HMPA, $-78^{\circ} \mathrm{C}$ ) followed by dropwise addition of $p$-benzoquinone dimethyl ketal, afforded conjugate addition adduct as a dienolate. Warming to $0{ }^{\circ} \mathrm{C}$, and addition of water to this dienolate presumably quenched the ketone enolate, leaving the nitronate anion intact which then underwent intramolecular cyclization. Finally, workup by the addition of $1.0 \mathrm{M} \mathrm{HCl}$ provided the [3.2.1]bicyclooctanones $\mathbf{2 a}$ and $\mathbf{2} \mathbf{b}$ as a ca. 1.4:1 inseparable mixture of diastereomers after silica gel chromatography in $51-59 \%$ yield (Table, entry 1 ). 
When either no additive or DMPU was used in these reactions, the yield dropped precipitously, but TMEDA can be used with only a minimal decrease in yield (cf. etnries 2-4). Furthermore, reaction efficiency is increased when an excess of quinone ketal is used relative to ethyl 3nitropropionate (cf. entries 1, 5-7). Interestingly, a combination of HMPA and TMEDA was superior to either additive alone (cf. entry 1,4 , and 8 ). ${ }^{9}$ The reaction could be easily scaled to up to provide ca. $10 \mathrm{~g}$ of $\mathbf{2 a}, \mathbf{b}$.

The mixture of diastereomers 2 quantitatively converged onto unsaturated ester $\mathbf{6}$ by DBUmediated elimination and filtration through a plug of silica gel (Scheme 3). We then focused on the regio- and stereoselective incorporation of the spirooxindole. After some experimentation, we were gratified - if surprised -to find that treatment with LiHMDS at -78 ${ }^{\circ} \mathrm{C}$ followed by the addition of 2-bromophenyl isocyanate and warming to room temperature provided $\beta$-keto anilide 7 as a single regioisomer in $62 \%$ yield. $5 \mathrm{~d}, 10$ Apparently, the ethyl ester blocks either deprotonation or electrophilic attack leading to the undesired regioisomer. Initial attempts to carry out a spirocyclization reaction at the oxidation level of keto amide (e.g., by conversion to the OMOM ether and Heck reaction ${ }^{5 \mathrm{f}}$ ) failed. Taking another tack, we found that $\beta$-keto anilide 7 could be reduced to the corresponding olefin by conversion to enol triflate $8\left(\mathrm{Tf}_{2} \mathrm{O}, \mathrm{TEA}\right)$ followed by Pd-catalyzed reduction $\left(n-\mathrm{Bu} 3 \mathrm{SnH}, 4 \mathrm{~mol} \% \mathrm{Pd}\left(\mathrm{PPh}_{3}\right)_{4}\right)$. This provided unsaturated anilide 9 in excellent yield without disturbing the aryl bromide. $N$ Methoxymethyl protection of this compound gave Heck cyclization precursor $\mathbf{1 0}$.

With 10 in hand, a number of Heck reaction conditions were surveyed. ${ }^{11}$ Though none of the conditions we investigated were highly diastereoselective, nearly complete conversion to the desired spirooxindole 11a and its epimer 11b was possible when $10 \mathrm{~mol} \% \mathrm{Pd}\left(\mathrm{PPh}_{3}\right)_{4}$ was used and the reaction was heated at $85^{\circ} \mathrm{C}$ in a microwave reactor. ${ }^{12}$ Lower conversions were observed when the reaction was carried out under oil bath conditions, although a rigorous comparison was not made.

To effect elongation at $\mathrm{C} 20$, we sought conditions to deprotect the dimethyl ketal while leaving the $\mathrm{N}$-methoxymethyl group intact. After some experimentation, it was found that by treating 11a with 1.5 equiv of $\mathrm{BF}_{3} \cdot \mathrm{OEt}_{2}$ at $0{ }^{\circ} \mathrm{C}$ for $20 \mathrm{~min}$, clean conversion to the ketone was possible without affecting the MOM group (Scheme 4). Following the precedent established by Fukuyama's group, $, 5 e, 6$ one-carbon elongation of this ketone was achieved by HornerWadsworth-Emmons reaction with tert-butyl diethylphosphonoacetate, which gave olefin isomers 12a and 12b in $61 \%$ and $23 \%$ yield, respectively. 1,4-Addition of methylamine to 12a proceeded quantitatively and was completely diastereoselective. To complete the synthesis of 3, Alloc-protection was performed on the resulting amino ester (AllocCl, pyridine, 4-DMAP, 92\%), followed by reduction with $\mathrm{LiBH}_{4}$ in $\mathrm{THF}(57 \%)$, and finally acetylation. The spectral data obtained for $\mathbf{3}$, which was converted to ( \pm )-gelsemine in 13 steps and $9.2 \%$ overall yield, matched those reported by Fukuyama and coworkers ( ${ }^{1} \mathrm{H}$ NMR, ${ }^{13} \mathrm{C}$ NMR, IR). $5 \mathrm{e}$

In summary, we have extended our previous work ${ }^{7}$ by showing that it is possible to construct a [3.2.1] bicyclooctanone via the double conjugate addition of a 1,2-bisnucleophile to a quinone ketal. In addition, we have demonstrated the utility of the product as an intermediate in complex natural product synthesis by converting it into an advanced gelsemine intermediate (and in so doing report a formal synthesis of this popular target). We are currently examining the scope of this approach to complex alkaloids.

\section{Supplementary Material}

Refer to Web version on PubMed Central for supplementary material. 


\section{Acknowledgements}

We thank Angelica Meyer of this laboratory for help with the optimization of the double conjugate additions. We thank the National Institutes of Health for financial support via GM-49093. S.G. gratefully acknowledges receipt of a Madison and Lila Self Graduate Fellowship.

\section{References}

1. Wormley TG. Am J Pharm 1870;42:1-16.

2. Conroy H, Chakrabarti JK. Tetrahedron Lett 1959;1:6-13.

3. Lovell FM, Pepinsky R, Wilson AJC. Tetrahedron Lett 1959;1:1-5.

4. Lin H, Danishefsky SJ. Angew Chem Int Ed 2003;42:36-51.

5. (a) Sheikh Z, Steel R, Tasker AS, Johnson AP. J Chem Soc, Chem Commun 1994:763-764. (b) Dutton JK, Steel RW, Tasker AS, Popsavin V, Johnson AP. J Chem Soc, Chem Commun 1994:765-766. (c) Newcombe NJ, Ya F, Vijn RJ, Hiemstra H, Speckamp WN. J Chem Soc, Chem Commun 1994:767768. (d) Atarashi S, Choi JK, Ha DC, Hart DJ, Kuzmich D, Lee CS, Ramesh S, Wu SC. J Am Chem Soc 1997;119:6226-6241. (e) Fukuyama T, Liu G. J Am Chem Soc 1996;118:7426-7427. (f) Madin A, O’Donnell CJ, Oh T, Old DW, Overman LE, Sharpe MJ. Angew Chem Int Ed 1999;38:2934-2936. (g) Ng FW, Lin H, Danishefsky SJ. J Am Chem Soc 2002;124:9812-9824. [PubMed: 12175241]

6. Yokoshima S, Tokuyama H, Fukuyama T. Angew Chem Int Ed 2000;39:4073-4075.

7. Grecian S, Wrobleski AD, Aubé J. Org Lett 2005;7:3167-3170. [PubMed: 16018612]

8. Seebach D, Henning R, Mukhopadhyay T. Chem Ber 1982;115:1705-1720.

9. Collum DB. Acc Chem Res 1992;25:448-454.

10. Hendi SB, Hendi MSH, Wolfe JF. Synth Commun 1987;17:13-18.

11. (a) For a review of Heck reactions in total synthesis, see:

LinkJTOvermanLEDiederichFStangPIntramolecular Heck reactions in Natural Product Chemistry. Metal-Catalyzed Cross-Coupling ReactionsWiley-VCHNew York1998231269(b)

EarleyWGOhTOvermanLETetrahedron Lett19882937853788 (c) Madin A, O’Donnell CJ, Oh T, Old DW, Overman LE, Sharp MJ. J Am Chem Soc 2005;127:18054-18065. [PubMed: 16366557] Also see references $5 \mathrm{c}$ and $5 \mathrm{f}$

12. The stereochemistry of the spirooxindoles was determined by NOE spectroscopy for each diastereomer. See Supporting Information for details 


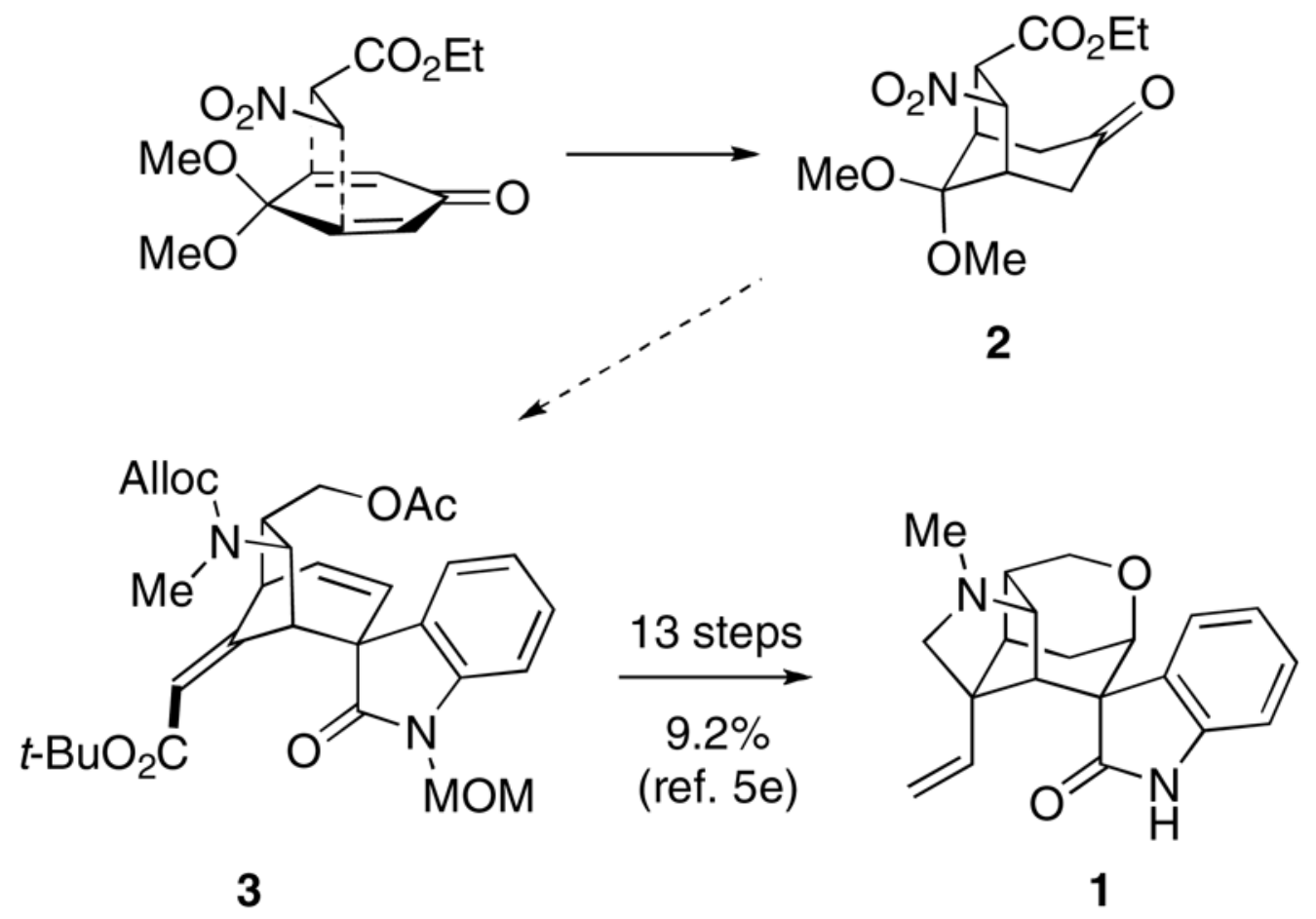

Scheme 1.

Strategy for Gelsemine Synthesis 
Previously<smiles>CCOC1(OCC)C=CC(=O)C(C(=O)OC)=C1</smiles>

4

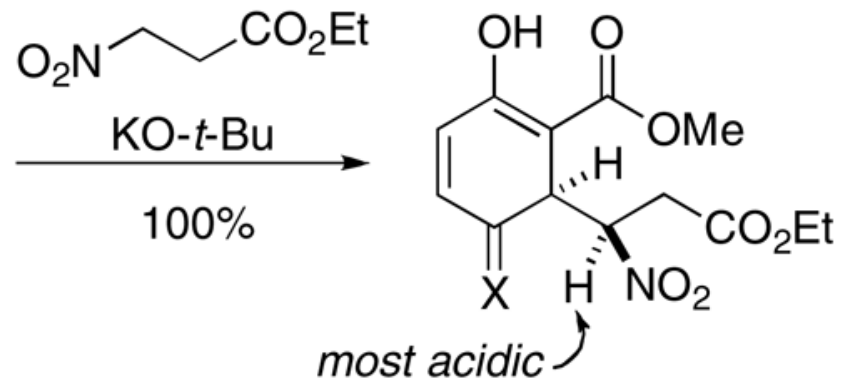

5 (X = diethyl ketal)

\section{This study}
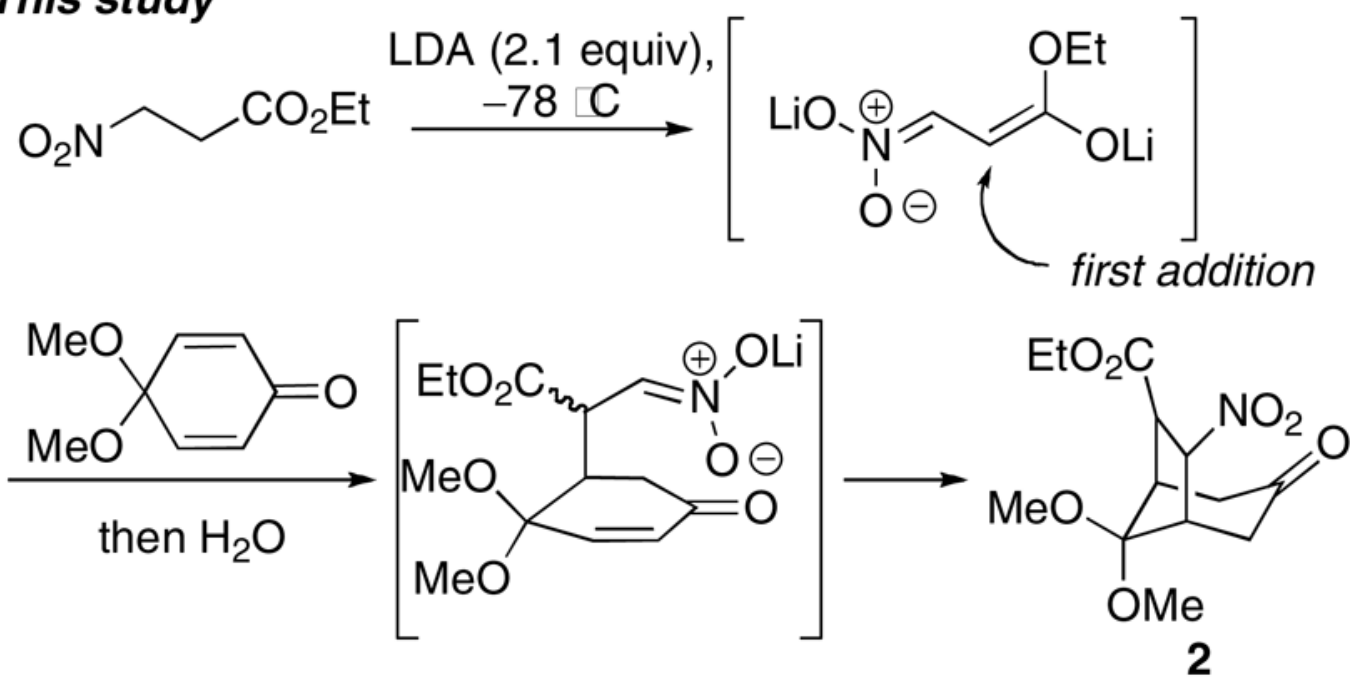

Scheme 2.

Conjugate Addition Reactions 
<smiles>CCOC(=O)CC1CC(=O)CC(C(OC)(OC)OC)C1[N+](=O)[O-]</smiles>

2a<smiles>CCOC(=O)C1C(OC)C2CC(=O)CC1C2(OC)OC</smiles>

2b

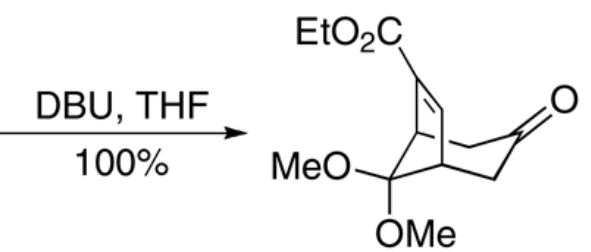

6

( 1.4:1 mixture)

i. LiHMDS, Š78 C THF, HMPA, $2 \mathrm{~h}$

ii. 2-bromophenyl isocyanate, $12 \mathrm{~h}$ $62 \%$

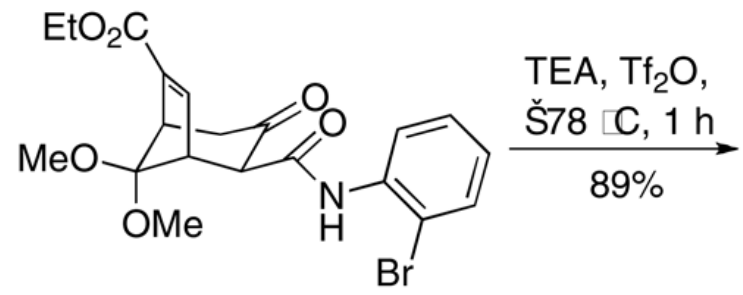

7

single regioisomer<smiles>CCOCC1=C([O])CC2C(C(=O)Nc3ccccc3Br)=C([O])C1C2(OC)OC</smiles>

8
$\mathrm{Pd}\left(\mathrm{PPh}_{3}\right)_{4}(4 \mathrm{~mol} \%), \quad \mathrm{EtO}_{2} \mathrm{C}$ $n-\mathrm{Bu}_{3} \mathrm{SnH}, \mathrm{LiCl}$, THF, rt, 20 min $94 \%$<smiles>COC1(OC)C(C(=O)Nc2ccccc2Br)=C2CCC1C(C)C2</smiles>

9

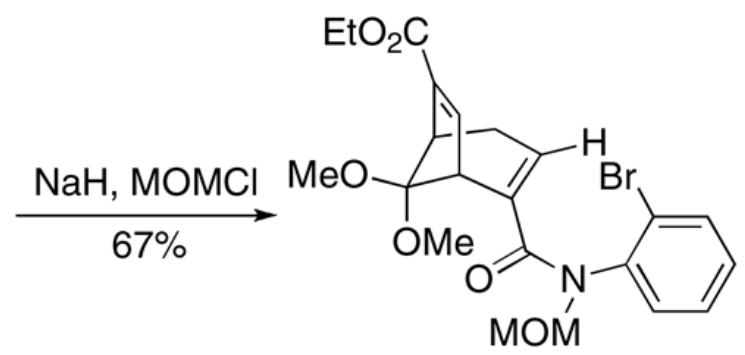

10

Scheme 3.

Preparation of Heck Precursor 10 

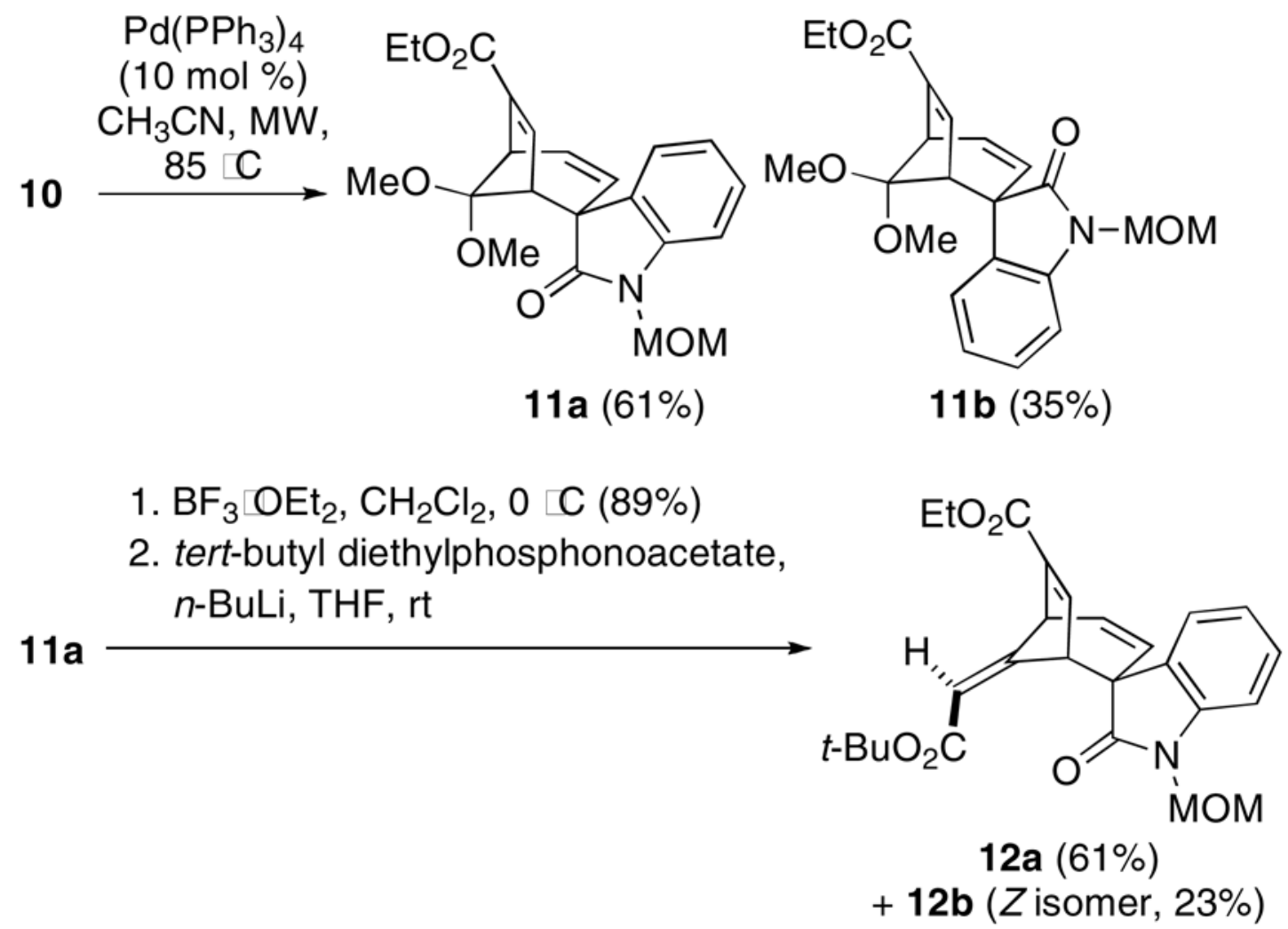

1. $\mathrm{NH}_{2} \mathrm{Me}, \mathrm{MeOH}, \mathrm{rt}(100 \%)$

2. AllocCl, pyr, 4-DMAP (92\%)

3. $\mathrm{LiBH}_{4}, \mathrm{THF}$, rt (57\%)

4. $\mathrm{Ac}_{2} \mathrm{O}, \mathrm{Et}_{3} \mathrm{~N}, 4-\mathrm{DMAP}(100 \%)$

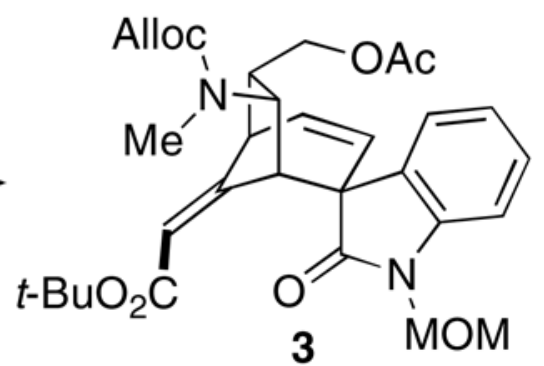

Scheme 4.

Completion of Fukuyama's Gelsemine Intermediate 
Table 1

Survey of Conditions for Double Conjugate Addition Reactions

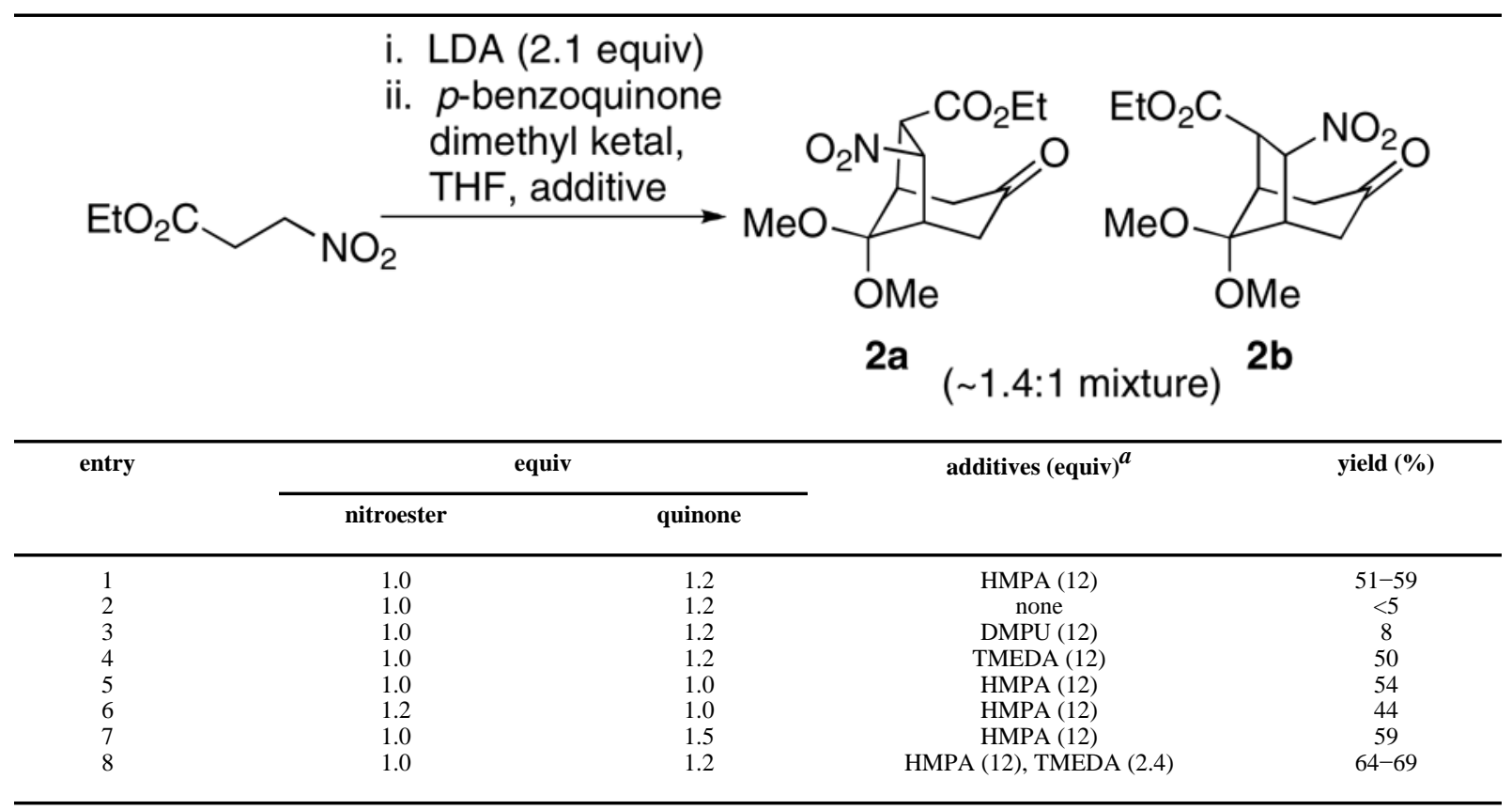

${ }^{a}$ Based on ethyl 3-nitropropionate. 